\title{
Anatomic Anteversion of the Acetabular Component Correlates with Polyethylene Linear Wear in Total Hip Arthroplasty: The Three-Dimensional Numerical Analysis
}

\author{
Ima Kosukegawa1, Satoshi Nagoya ${ }^{2}$, Mitsunori Kaya1, Mikito Sasaki', Shunichiro Okazaki², \\ Daisuke Suzuki², Toshihiko Yamashita ${ }^{1}$ \\ ${ }^{1}$ Department of Orthopedic Surgery, Sapporo Medical University, Sapporo, Japan \\ ${ }^{2}$ Department of Musculoskeletal Biomechanics and Surgical Development, Sapporo Medical University, \\ Sapporo, Japan \\ Email: imakosukegawa@gmail.com
}

Received 11 April 2016; accepted 28 May 2016; published 31 May 2016

Copyright (C) 2016 by authors and Scientific Research Publishing Inc.

This work is licensed under the Creative Commons Attribution International License (CC BY).

http://creativecommons.org/licenses/by/4.0/

c) (i) Open Access

\begin{abstract}
Background: Although abduction of the acetabular component is considered to predict factors for polyethylene wear attributable to osteolysis, other radiographic factors have yet to be elucidated. The purpose of the present study was to evaluate whether anteversion or change in implantation angle of the acetabular component influences polyethylene linear wear by using standing and supine radiographs of the hip joint. Methods: Standing and supine plain anteroposterior radiographs of 62 hip joints in which cementless total hip arthroplasty was performed were examined for polyethylene linear wear rate ( $\mathrm{mm} / \mathrm{year})$, pelvic inclination, and radiological inclination and anatomic anteversion of the acetabular component. Results: All correlation coefficients of measurements of polyethylene linear wear, pelvic inclination angle, anatomical anteversion angle and radiological inclination angle were calculated highly. And by the three-dimensional numerical analysis, anatomic anteversion of the acetabular component had at least some effect on the degree of polyethylene wear. Conclusion: This study suggests that increased anteversion of the acetabular component reduces polyethylene linear wear in metal-on-polyethylene total hiparthroplasty.
\end{abstract}

\section{Keywords}

Total Hiparthroplasty, Polyethylene Linear Wear, Standing Position, Settingangle of Acetabular Component 


\section{Introduction}

Implant loosening is a clinical and radiographic complication after metal-on-polyethylene total hip arthroplasty (THA); presence of a large number of worn polyethylene particles is considered a key factor in the onset of periprostheticosteolysis. Younger age, thinner polyethylene, and larger implant head size have been acknowledged for their adverse effects on polyethylene wear [1] [2]. The position and implantation angle of the acetabular component is also related to polyethylene wear, with increased abduction shown to be a particularly important postoperative factor, as evaluated on anteroposterior radio graphs of the hip joint. However, the effects of other factors of implantation angle on osteolysis have not been explored.

Several factors are yet to be investigated, such as anteversion of the acetabular component and change in implantation angle upon pelvic inclination. Lewinnek reported that adequate anteversion of the acetabular component should be $15^{\circ} \pm 10^{\circ}$ from a standpoint of dislocation [3]. Widmer also recommended adequate anteversion of the acetabular component to prevent postoperative dislocation, but they did not evaluate polyethylene wear [4]. Another point to be investigated is the effect of pelvic inclination on the acetabular component. Pelvic inclination might change according to the degree of lumbar lordosis in the supine or standing position. We consider that implantation angle of the acetabular component, previously regarded as appropriate in the supine position, might display beyond-normal range of adequate angles based on unexpected change in pelvic inclination. Although weight bearing might induce creep deformity of polyethylene [5] [6], change in implantation angle of the acetabular component has not been evaluated. Therefore, the purpose of the present study was to evaluate whether anteversion or change in implantation angle of the acetabular component influences polyethylene linear wear by using standing and supine radiographs of the hip joint.

\section{Materials and Methods}

\subsection{Patients and Methods}

We retrospectively studied 56 patients (4 men and 52 women) who underwent 62 primary or revision THA between 1991 and 2006. The patients comprised 4 men and 58 women with a mean age of 52 years (range, 35 - 70 years) at the time of surgery. The mean weight was $53 \mathrm{~kg}$ (range, $35-72 \mathrm{~kg}$ ), 6 patients underwent bilateral hip arthroplasty. The mean follow-up was 122 months (range, 42 - 228 months). The preoperative diagnosis was osteoartgritis in 10 hips, degenerative arthritis of developmental hip dysplasia in 44 hips, rheumatoid arthritis in 4 hips, aseptic loosening in 1 hip, failed bipolar hemiarthroplasty in 2 hips, tuberculous arthritis in 1 hip.

We examined standing and supine plain anteroposterior radiographs of the hip joint centered on the pubic symphysis, which were obtained at the final follow-up. This study was approved by the hospital science ethics committee of Sapporo Medical University (No 24 - 131) and informed consent was obtained from patients.

This study included that acetabular component used was either a 300 series Duraloc spiked titanium cementless cup or a 1200 series Duraloc titanium cementless cup (DePuy International, Leeds, United Kingdom) with screw fixation. Cobalt-chromium metal-on-conventional polyethylene Enduron (DePuy International) bearings were used throughout. The diameter of the metal head was $22.225 \mathrm{~mm}$. An AML Plus cementless cylindrical stem or an AML Replica cementless stem (DePuy International) was implanted.

We exclude patients, 1) radiographs in which the line between the sacrum and the coccyx did not lie on the pubic symphysis, 2) patients who had undergone bilateral THA with a long interval between the 2 operations so as to avoid measurement bias involving the influence of change in right and left pelvic inclinations. However, 6 patients (12 hips) who underwent bilateral THA within a one-year interval were enrolled in this study. We examined standing and supine radiographs for polyethylene linear wear rate ( $\mathrm{mm} / \mathrm{year})$, pelvic inclination, and radiological inclination and anatomical anteversion of the acetabular component, defined by Murray [7].

All measurements were performed using OP-1 radiographic measurement software (Fuji Film Co. Ltd. Tokyo. Japan). Polyethylene linear wear was expressed as the distance between the center of the acetabular component and the femoral head, according to the method of Sugano et al. [8]. Real wear values were compensated by calculating the difference between the measured diameter of the metal head on radiography and the actual diameter of the inserted femoral head. Pelvic inclination was measured according to the method of Doiguchi et al. [9]. Horizontal diameter $(\mathrm{T})$ and vertical diameter $(\mathrm{L})$ of the pelvic cavity on radiography were measured, and pelvic inclination was calculated using the following formulae: $-67 \times \mathrm{L} / \mathrm{T}+55.7$ for male hips and $-69 \times \mathrm{L} / \mathrm{T}+61.6$ for female hips (Figure 1). A larger pelvic inclination indicates posterior tilt of the pelvis. radiologicalinc lination of the acetabular component was defined as the angle between the line across the acetabular teardrops and 


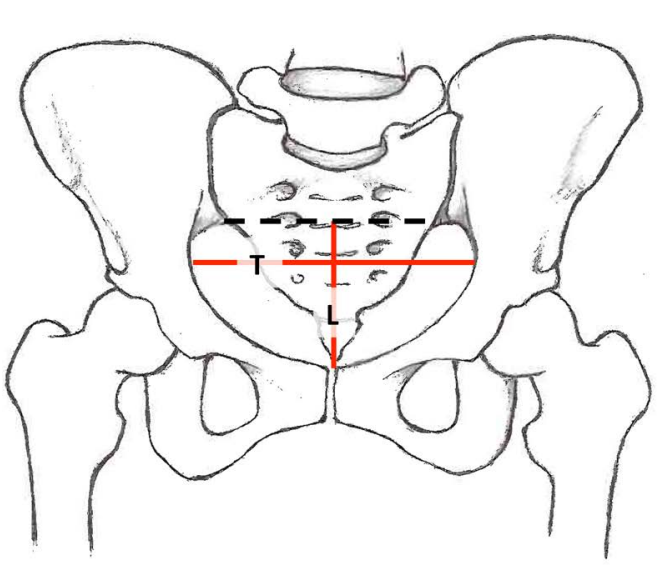

(a)

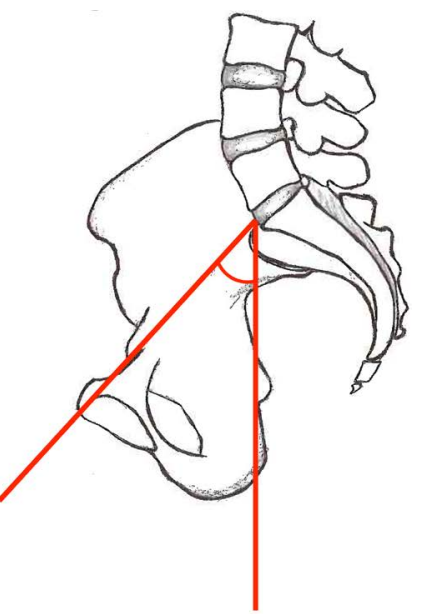

(b)

Figure 1. The method of radiographic measurement. T: The parallel line to reference line between the bottom of sacroiliac joints and maximal diameter of the pelvic cavity on radiography. L: The vertical line to the reference line and through top of the pubic symphysis (a). Pelvic inclination: The angle of the line between the sacral promontory and top of the pubic symphysis and the X-ray film plane (b).

the line through the maximum diameter of the acetabular component. Anatomic anteversion of the acetabular component was measured according to the method of Visser et al. [10] (Figure 2).

\subsection{Statistic Analysis}

\subsubsection{Comparison the Measurement Result Supine and Standing Position}

Regression line $\mathrm{Y}=\mathrm{aX}+\mathrm{b}$ was found assigned a measurement stnding to variable $\mathrm{Y}$, as supine to variable $\mathrm{X}$.

\subsubsection{Three-Dimensional Numerical Analysis}

We calculated operative anteversion and operative inclination in the following expression based on the anatomical anteversion and radiological inclination in the standing position.

$$
\begin{gathered}
\operatorname{Tan}(\mathrm{OA})=\operatorname{Tan}(\mathrm{AA}) \times \operatorname{Tan}(\mathrm{RI}) \\
\operatorname{Sin}(\mathrm{OI})=\frac{1}{\sqrt{\sin ^{-2}(\mathrm{RI})+\tan ^{2}(\mathrm{AA})}}
\end{gathered}
$$

A normal vector directs to the plane.

The three dimensional implantation angle was calculated back from this operative anteversion and operative inclination, and direction of acetabular component opening was showed by a plane parallel to the acetabular component opening with using three-dimensional normal vector. This normal vector ${ }^{t}(x, y, z)$ was calculated by using the following rotation matrix when the $\mathrm{Y}$ axis represents anteroposteroir direction of pelvis, the $\mathrm{X}$ axis represents the bilateral direction and the $\mathrm{Z}$ axis represents the upper and lower direction (Figure 3, Supplemental Table 1).

$$
\left(\begin{array}{l}
x \\
y \\
z
\end{array}\right)=\left(\begin{array}{ccc}
1 & 0 & 0 \\
0 & \cos (\mathrm{OA}) & -\sin (\mathrm{OA}) \\
0 & \sin (\mathrm{OA}) & \cos (\mathrm{OA})
\end{array}\right)\left(\begin{array}{ccc}
\cos (\mathrm{OI}) & 0 & \sin (\mathrm{OI}) \\
0 & 1 & 0 \\
-\sin (\mathrm{OI}) & 0 & \cos (\mathrm{OI})
\end{array}\right)\left(\begin{array}{c}
0 \\
0 \\
-1
\end{array}\right)
$$

Normal vectors calculated were projected on the $\mathrm{YZ}$ plane and each the side $\mathrm{Y}$ and $\mathrm{Z}$ divided into three equal parts, consequently, this plane was divided into 9 areas A-I (Figure 4(a), Figure 4(b)). We compared mean values of polyethylene linear wear in each area. This analysis was performed with using $3 \mathrm{D}$ graph soft ware (RINEARN Graph 3D, Kyoto, Japan). 


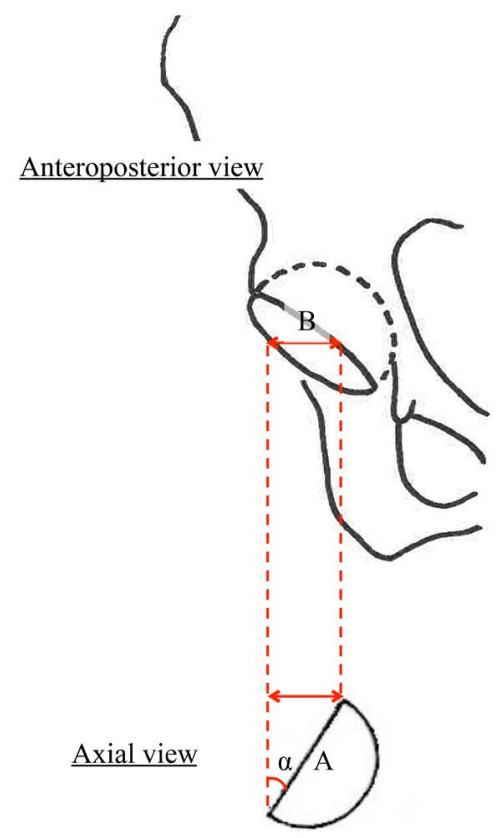

Figure 2. Calculation of anatomic anteversion of the implanted acetabular component using the fomula sin $\alpha=\mathrm{B} / \mathrm{A}$. A: acetabular component diameter. B: the distance measured from anteroposterior radiographs. $\alpha=$ anatomic antevertion.

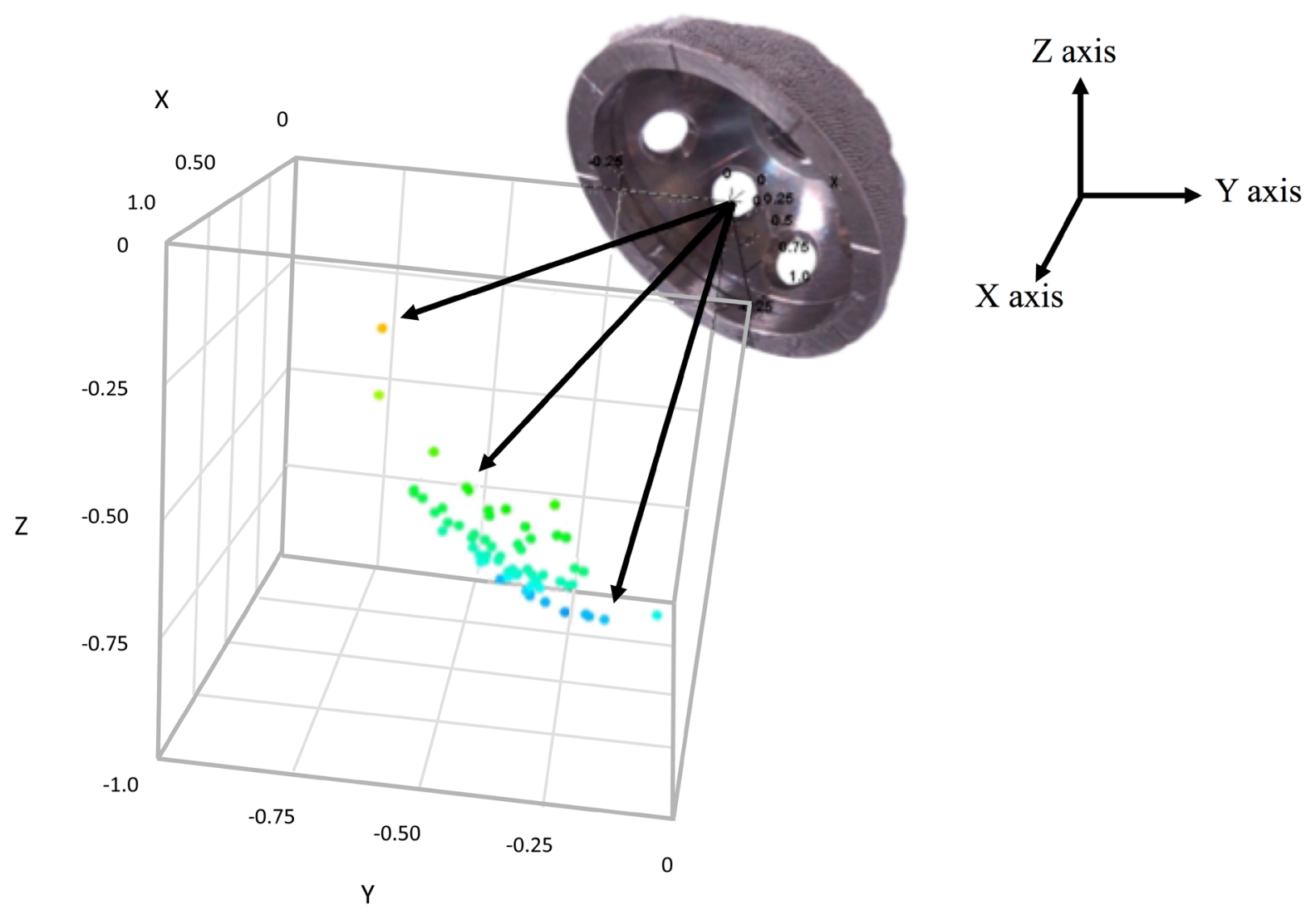

Figure 3. The relation between the acetabular component direction and the coordinate. When the left acetabular component is viewed from lateral side, a normal vector directs to the plane parallel to the acetabular compnent opening. All cases were replaced with left side in this figure. The acetabular component directs lateral when $\mathrm{X}$ is plus, similary, directs anterior when $\mathrm{Y}$ is minus, inferior when $\mathrm{Z}$ is minus. All normal vectors directied lateral and anterior, inferior. 


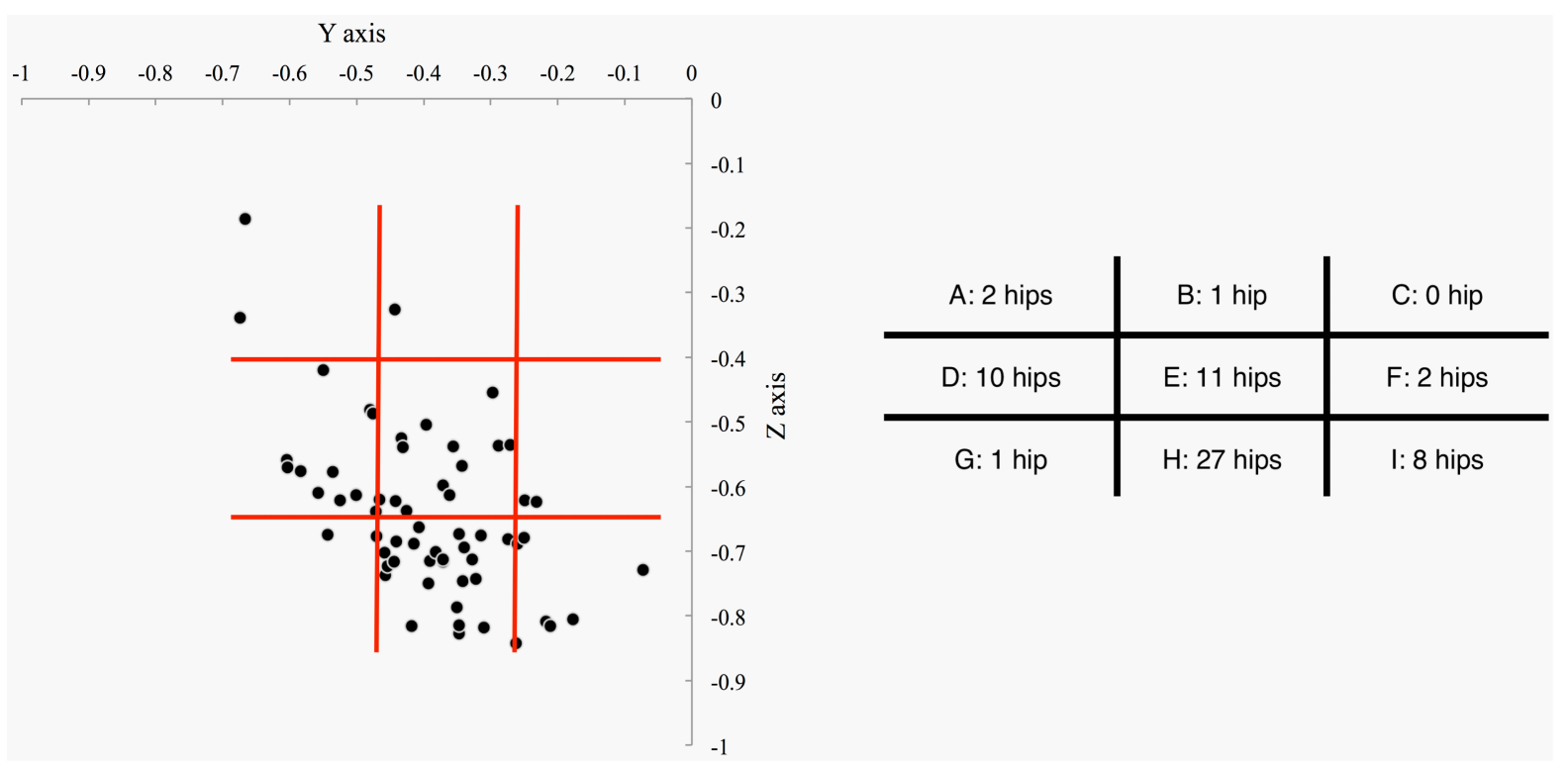

(a)

(b)

Figure 4. Grouping by directions of normal vectors (a). Each number of hips in 9 areas (b). Normal vectors in the group A, B, $\mathrm{C}$ are tend to face to the lateral direction, and normal vectors in the group $\mathrm{A}, \mathrm{D}, \mathrm{G}$ are tend to face to the anterior direction.

\section{Results}

\subsection{Comparison the Measurement Result Supine and Standing Position}

Table 1 showed regression lines of polyethylene linear wear, pelvic inclination angle, anatomical anteversion angle, radiological inclination angle. All correlation coefficients were calculated highly, 0.84 - 0.89.

\subsection{Three-Dimensional Numerical Analysis}

Figure 4(b) showed each number of hips in 9 areas. Mean value of polyethylene linear wear, pelvic inclination angle, anatomical anteversion angle, radiological inclination angle and operative anteversion angle were compared in each groups D, E, H, I which included three or more hip joints (Table 2).

Polyethylene linear wear of the group D was tend to be smaller and which of group I larger $(p=0.052)$.

\section{Discussion}

As factors related to increased polyethylene wear, patient characteristics as well as abduction of the acetabular component and femoral offset have been reported in several studies [11]-[15]. Some clinical reports have revealed that increased abduction of the acetabular component resulted in increased polyethylene linear wear [12] [16]. On the other hand, few reports suggest that the implantation angle of the acetabular component does not influence polyethylene wear [17] [18]. Despite many reports focusing on abduction, few have referred to anteversion of the acetabular component.

In terms of anteversion, appropriate implantation angle of the acetabular component recommended by Lewinnek [3] and Widmer [4] was aimed to prevent of postoperative dislocation of THA, however it was unclear whether polyethylene wear volume was decreased. We evaluated implantation angle of the acetabular component to define the effect for polyethylene wear.

We compared measurements of polyethylene linear wear, pelvic inclination, anatomical anteversion, radiological inclination in the supine and standing position. As a result, calculated regression lines showed all measurement supine were highly correlated with each measurement standing. Polyethylene linear wear was verified with higher precision in the standing position than supine position. However, we did not find increased polyethylene wear on the basis of change in posture.

The results of three-dimensional numerical analysis, we investigated that polyethylene linear wear of the group D was tend to be smaller and which of group I larger $(p=0.052)$. In the present study, when the absolute 
Table 1. A regression coefficient and a correlation coefficient calculated with measurements in the supine and standing position.

\begin{tabular}{cccc}
\hline & slope & Y intercept & correlation coefficient R \\
\hline WY (mm) & 0.95 & 0.019 & 0.86 \\
PIA $\left(^{\circ}\right)$ & 1.28 & 0.46 & 0.84 \\
AA $\left(^{\circ}\right)$ & 0.78 & 10.62 & 0.89 \\
RI $\left(^{\circ}\right)$ & 1.06 & 0.43 & 0.86 \\
\hline
\end{tabular}

WY: polyethylene linear wear, PIA: pelvic inclination angle; AA: anatomical anteversion angle, RI: radiological inclination angle.

Table 2. The mean value of polyethylene linear wear, pelvic inclination, anatomical anteversion, radiological inclination and operative anteversion of each groups.

\begin{tabular}{cccccc}
\hline & WY (mm/year) & PIA $\left(^{\circ}\right)$ & AA $\left({ }^{\circ}\right)$ & RI $\left(^{\circ}\right)$ & OA $\left(^{\circ}\right)$ \\
\hline Total & 0.118 & 30.2 & 33.1 & 43.6 & 32.1 \\
Group D & 0.095 & 32.8 & 43.0 & 46.5 & 44.6 \\
Group E & 0.128 & 32.0 & 28.2 & 52.0 & 34.3 \\
Group H & 0.116 & 26.5 & 34.9 & 37.6 & 28.1 \\
Group I & 0.141 & 26.8 & 19.3 & 39.3 & 15.8 \\
\hline
\end{tabular}

value on a $\mathrm{Y}$ axis is larger, anteversion is larger. Similarly, when the absolute value on a $\mathrm{Z}$ axis is larger, abduction is larger. Therefore normal vectors in the group A, B, C are tend to face to the lateral direction, and normal vectors in the group A, D, G are tend to face to the anterior direction. This result suggested a relevance between polyethylene linear wear and anatomical anteversion, operative anteversion, because larger data of anatomical anteversion and operative anteversion was distributed into group D, also smaller data of anatomical anteversion and operative anteversion was distributed into group I. Although Wan et al. measured anteversion of the acetabular component clinically, they did not refer to polyethylene wear [13]. Patil et al. reported that increased abduction of the acetabular component led to elevated contact stress on the articulation surface, whereas increased anteversion led to decreased contact stress in a finite element model [16]. D'Lima et al. reported similar experimental results [19].

Our study revealed that increased anatomic anteversion of the acetabular component resulted in decreased polyethylene wear and confirmed the experimental results of the finite element analysis performed to determine contact stress on the weight-bearing rim.

Thus, this study proved that anatomic anteversion of the acetabular component had at least some effect on the degree of polyethylene wear.

This study was limited by a lack of information regarding position of the acetabular component, creep deformity, and deviation of the femoral head in the anteroposterior direction. Further studies will be necessary to investigate polyethylene wear.

\section{Conclusions}

We investigated whether anteversion of the acetabular component has an influence on polyethylene linear wear. Standing and supine plain anteroposterior radiographs of 62 hip joints in which total hip arthroplasty was performed were evaluated for polyethylene linear wear rate (mm/year), pelvic inclination, and abduction and anatomic anteversion of the acetabular component.

Pelvic inclination as well as operative anteversion and anatomic anteversion of the acetabular component increased in the standing position compared with that in the supine position.

By the three-dimensional numerical analysis, increased anteversion of the acetabular component reduces polyethylene linear wear in metal-on-polyethylene total hip arthroplasty. 


\section{References}

[1] Devane, P.A. and Horne, J.G. (1999) Assessment of Polyethylene Wear in Total Hip Replacement. Clinical Orthopaedics and Related Research, 369, 59-72. http://dx.doi.org/10.1097/00003086-199912000-00007

[2] Livermore, J., Ilstrup, D. and Morrey, B. (1990) Effect of Femoral Head Size on Wear of the Polyethylene Acetabular Component. The Journal of Bone \& Joint Surgery American Volume, 72, 518-528.

[3] Lewinnek, G.E., Lewis, J.L., Tarr, R. Compere, C.L. and Zimmerman, J.R. (1978) Dislocations after Total HipReplacement Arthroplasties. The Journal of Bone \& Joint Surgery American Volume, 60, 217-220.

[4] Widmer, K.H. and Zurfluh, B. (2004) Compliant Positioning of Total Hip Components for Optimal Range of Motion. Journal of Orthopaedic Research, 22, 815-821. http://dx.doi.org/10.1016/j.orthres.2003.11.001

[5] Smith, P.N., Ling, R.S. and Taylor, R. (1999) The Influence of Weight-Bearing on the Measurement of Polyethylene Wear in THA. The Journal of Bone \& Joint Surgery British Volume, 81, 259-265. http://dx.doi.org/10.1302/0301-620X.81B2.9154

[6] Martell, J.M., Leopold, S.S. and Liu, X. (2000) The Effect of Joint Loading on Acetabular Wear Measurement in Total Hip Arthroplasty. The Journal of Arthroplasty, 15, 512-518. http://dx.doi.org/10.1054/arth.2000.4336

[7] Murray, D.W. (1993) The Definition and Measurement of Acetabular Orientation. The Journal of Bone \& Joint Surgery British Volume, 75, 228-32.

[8] Sugano, N., Nishii, T., Nakata, K., Masuhara, K. and Takaoka, K. (1995) Polyethylene Sockets and Alumina Ceramic Heads in Cemented Total Hip Arthroplasty. A Ten-Year Study. The Journal of Bone \& Joint Surgery British Volume, 77, 548-556.

[9] Doiguchi, Y., Iwasaki, K., Yamada, K., Takahashi, K., Teshima, K., Sasamatsu, T., Tomita, M. and Narabayashi, Y. (1992) Correlation between Pelvic Inclination and Radiological Shape of the Pelvic Cavity. Orthopedics \& Traumatology, 41, 641-645. (In Japanese) http://dx.doi.org/10.5035/nishiseisai.41.641

[10] Visser, J.D. and Konings, J.G. (1981) A New Method for Measuring Angles after Total Hip Arthroplasty. A Study of the Acetabular Cup and Femoral Component. The Journal of Bone \& Joint Surgery British Volume, 63, 556-559.

[11] Georgiades, G., Babis, G.C., Kourlaba, G. and Hartofilakidis, G. (2010) Effect of Cementless Acetabular Component Orientation, Position, and Containment in Total Hip Arthroplasty for Congenital Hip Disease. The Journal of Arthroplasty, 25, 1143-1150. http://dx.doi.org/10.1016/j.arth.2009.12.016

[12] Little, N.J., Busch, C.A., Gallagher, J.A., Rorabeck, C.H. and Bourne, R.B. (2009) Acetabular Polyethylene Wear and Acetabular Inclination and Femoral Offset. Clinical Orthopaedics and Related Research, 467, 2895-2900. http://dx.doi.org/10.1007/s11999-009-0845-3

[13] Wan, Z., Boutary, M. and Dorr, L.D. (2008) The Influence of Acetabular Component Position on Wear in Total Hip Arthroplasty. The Journal of Arthroplasty, 23, 51-56. http://dx.doi.org/10.1016/j.arth.2007.06.008

[14] Bicanic, G., Delimar, D., Delimar, M. and Pecina, M. (2009) Influence of the Acetabular Cup Position on Hip Load during Arthroplasty in Hip Dysplasia. International Orthopaedics, 33, 397-402. http://dx.doi.org/10.1007/s00264-008-0683-z

[15] Sakalkale, D.P., Sharkey, P.F., Eng, K., Hozack, W.J. and Rothman, R.H. (2001) Effect of Femoral Component Offset on Polyethylene Wear in Total Hip Arthroplasty. Clinical Orthopaedics and Related Research, 388, 125-134. http://dx.doi.org/10.1097/00003086-200107000-00019

[16] Patil, S., Bergula, A., Chen, P.C., Colwell Jr., C.W. and D’Lima, D.D. (2003) Polyethylene Wear and Acetabular Component Orientation. The Journal of Bone \& Joint Surgery American Volume, 85, 56-63.

[17] Goosen, J.H., Verheyen, C.C. and Tulp, N.J. (2005) Mid-Term Wear Characteristics of an Uncemented Acetabular Component. The Journal of Bone \& Joint Surgery British Volume, 87, 1475-1479. http://dx.doi.org/10.1302/0301-620X.87B11.16101

[18] Del Schutte Jr., H., Lipman, A.J., Bannar, S.M., Livermore, J.T., Ilstrup, D. and Morrey, B.F. (1998) Effects of Acetabular Abduction on Cup Wear Rates in Total Hip Arthroplasty. The Journal of Arthroplasty, 13, 621-626. http://dx.doi.org/10.1016/S0883-5403(98)80003-X

[19] D’Lima, D.D., Chen, P.C. and Colwell Jr., C.W. (2001) Optimizing Acetabular Component Position to Minimize Impingement and Reduce Contact Stress. The Journal of Bone \& Joint Surgery American Volume, 83, 87-91. 
Supplemental Table 1. The mean value of polyethylene linear wear, pelvic inclination, anatomical anteversion, radiological inclination and operative anteversion of each groups.

\begin{tabular}{|c|c|c|c|}
\hline & $\mathrm{X}$ & $\mathrm{Y}$ & $\mathrm{Z}$ \\
\hline patient 1 & 0.466 & -0.347 & -0.814 \\
\hline patient 2 & 0.507 & -0.351 & -0.787 \\
\hline patient 3 & 0.667 & -0.314 & -0.675 \\
\hline patient 4 & 0.565 & -0.177 & -0.806 \\
\hline patient 5 & 0.748 & -0.342 & -0.569 \\
\hline patient 6 & 0.399 & -0.419 & -0.816 \\
\hline patient 7 & 0.702 & -0.362 & -0.614 \\
\hline patient 8 & 0.620 & -0.328 & -0.713 \\
\hline patient 9 & 0.608 & -0.471 & -0.639 \\
\hline patient 10 & 0.442 & -0.347 & -0.827 \\
\hline patient 11 & 0.617 & -0.535 & -0.577 \\
\hline patient 12 & 0.793 & -0.289 & -0.537 \\
\hline patient 13 & 0.566 & -0.470 & -0.677 \\
\hline patient 14 & 0.499 & -0.544 & -0.674 \\
\hline patient 15 & 0.558 & -0.603 & -0.570 \\
\hline patient 16 & 0.591 & -0.371 & -0.716 \\
\hline patient 17 & 0.677 & -0.260 & -0.689 \\
\hline patient 18 & 0.545 & -0.458 & -0.703 \\
\hline patient 19 & 0.800 & -0.271 & -0.536 \\
\hline patient 20 & 0.539 & -0.444 & -0.716 \\
\hline patient 21 & 0.722 & -0.667 & -0.186 \\
\hline patient 22 & 0.768 & -0.396 & -0.504 \\
\hline patient 23 & 0.732 & -0.476 & -0.487 \\
\hline patient 24 & 0.595 & -0.371 & -0.713 \\
\hline patient 25 & 0.581 & -0.441 & -0.684 \\
\hline patient 26 & 0.628 & -0.407 & -0.663 \\
\hline patient 27 & 0.645 & -0.442 & -0.623 \\
\hline patient 28 & 0.579 & -0.391 & -0.715 \\
\hline patient 29 & 0.764 & -0.356 & -0.538 \\
\hline patient 30 & 0.595 & -0.414 & -0.689 \\
\hline patient 31 & 0.657 & -0.674 & -0.339 \\
\hline patient 32 & 0.835 & -0.444 & -0.326 \\
\hline patient 33 & 0.484 & -0.310 & -0.818 \\
\hline patient 34 & 0.722 & -0.550 & -0.420 \\
\hline patient 35 & 0.678 & -0.275 & -0.682 \\
\hline patient 36 & 0.571 & -0.342 & -0.746 \\
\hline patient 37 & 0.710 & -0.371 & -0.598 \\
\hline patient 38 & 0.732 & -0.434 & -0.526 \\
\hline
\end{tabular}




\section{Continued}

patient 39

patient 40

patient 41

patient 42

patient 43

patient 44

patient 45

patient 46

patient 47

patient 48

patient 49

patient 50

patient 51

patient 52

patient 53

patient 54

patient 55

patient 56

patient 57

patient 58

patient 59

patient 60

patient 61

patient 62

Mean

SD
0.601

0.572

0.568

0.582

0.611

0.547

0.733

0.564

0.520

0.840

0.746

0.538

0.632

0.653

0.690

0.642

0.498

0.743

0.634

0.680

0.470

0.723

0.532

0.587

0.6260

0.0999
$-0.382$

$-0.584$

$-0.604$

$-0.525$

$-0.500$

$-0.218$

$-0.481$

$-0.557$

$-0.454$

$-0.298$

$-0.231$

$-0.211$

$-0.466$

$-0.347$

$-0.250$

$-0.426$

$-0.458$

$-0.249$

$-0.339$

$-0.072$

$-0.263$

$-0.432$

$-0.393$

$-0.322$

$-0.3956$

0.1193
$-0.702$

$-0.576$

$-0.559$

$-0.621$

$-0.614$

$-0.808$

$-0.481$

$-0.609$

$-0.723$

$-0.454$

$-0.624$

$-0.816$

$-0.620$

$-0.673$

$-0.679$

$-0.637$

$-0.737$

$-0.621$

$-0.695$

$-0.729$

$-0.843$

$-0.539$

$-0.750$

$-0.743$

$-0.6414$

0.12934 